\title{
STUDY OF THE PULMONARY HYPERTENSION AND PULMONARY VESSELS MEASUREMENTS USING COMPUTED TOMOGRAPHY
}

\author{
Samia Abdelgaum Fathelrahman ${ }^{1}$ (1) and Maha Esmeal Ahmed Esmeal $^{2}$ (1) \\ ${ }^{1}$ Assistant Professor, Department of Radiological Sciences, Applied Medical College, Najran University, Kingdom of Saudi \\ Arabia \\ ${ }^{2}$ Associate Professor, Radiography and Medical Imaging Sciences, Radiological Sciences College, National University, Sudan
}
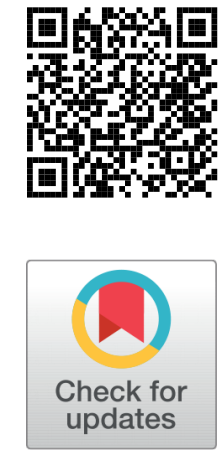

Received 20 March 2021

Accepted 6 April 2021

Published 30 April 2021

Corresponding Author

Samia Abdelgaum Fathelrahman, s

amia-radiology@hotmail.com

DOI $10.29121 /$

granthaalayah.v9.i4.2021.3820

Funding: This research received no specific grant from any funding agency in the public, commercial, or not-for-profit sectors.

Copyright: (C) 2021 The Author(s). This is an open access article distributed under the terms of the Creative Commons Attribution License, which permits unrestricted use, distribution, and reproduction in any medium, provided the original author and source are credited.

\section{ABSTRACT}

The purpose of the study was to study the pulmonary vessels in patients with pulmonary hypertension using Computed Tomography scan (CT) This is a prospective ,analytical study. this study was conducted at Khartoum Hospital (Sudan); in the period between November 2020 - January 2021 a sample of (100) patients with clinically diagnosed as pulmonary hypertension was enrolled, their mean ages were $(47.92 \pm 19.03)$ years, the sample included both genders, (42) patients were females while (58) were males and their ages were ranged from (3 - 80) years old. (CTPA) scans were acquired, all patients were examined by using multislice (CT) scanner, the data collected by special designed sheet from findings and analyzed statistically by using an (SPSS) Statistics software package. The sample was directed to study the relationship of pulmonary hypertension with the presence of pulmonary vessels measurements; the patient's age and gender correlation with the pulmonary hypertension were investigated. The results find that the right and left main pulmonary arteries diameters changes were found to be significantly related to the presence of pulmonary hypertension, while there was no significant difference in the main pulmonary artery diameters measurements. The study concluded that CT for pulmonary artery plays an important role in the diagnostic evaluation of patients with pulmonary hypertension this due to it is easily accessible and excellent non-invasive method for the visualization and measurement of pulmonary artery and to know the possible cause of pulmonary hypertension.

Keywords: Pulmonary Hypertension, Computed Tomography, Pulmonary Arterial Hypertension, Pulmonary Artery Diameter, Characterization 


\section{INTRODUCTION}

Pulmonary vascular disease span a variety of disease entities including pulmonary arterial hypertension (PAH), pulmonary venous hypertension, pulmonary embolism, pulmonary arteriovenous malformation, pulmonary arterial stenosis, pulmonary arterial aneurysm, pulmonary veno-occlusive disease (PVOD) and pulmonary capillary hemangiomatosis. Araoz et al. (2003); Bergin et al. (1999); Singanayagam et al. (2010). Chest computed tomography (CT) is widely used for evaluation of lung diseases and CT measurements correlated well with the COPD assessment test.6 In addition, CT is a useful tool for thoracic vascular assessment. It could detect changes of small vessels, and these anomalies are important for clinical implications Estepar et al. (2013); WASHKO et al. (2012)

Pulmonary hypertension is a serious condition characterized by higher than normal pressure in the blood vessels between the lungs and the heart. PH has nonspecific symptoms that make it difficult to diagnose non-invasively. Consequently, patient evaluation normally requires numerous diagnostic tests. The diagnostic evaluation of PH includes physical exam, electrocardiography, pulmonary function tests, blood gas analysis, ventilation/perfusion (V/Q) scan, echocardiography, and RHC with vasodilatory testing. Although RHC is the gold standard for the diagnosis of PH Badesch and B (2009)

Suspected PH patients have a thoracic computed tomography (CT) scan to investigate the lung parenchyma, to detect thromboembolic disease, and to evaluate anatomic adaptations that may result from $\mathrm{PH}$, such as increased pulmonary artery diameter and vascular pruning. KURIYAMA et al. (1984)

In the body of a healthy person, oxygen-poor blood returning to the heart from all body organs and tissues, travels from the right side of the heart through the pulmonary arteries into the lungs. Within the lungs, these arteries divide into smaller vessels in order to acquire oxygen and eliminate carbon dioxide. The oxygen-rich blood then returns to the left side of the heart from where it is pumped with freshly oxygenated blood back to all body organs and tissues. In pulmonary hypertension, the pressure of blood in the lungs is increased either because the blood vessels are narrowed (a lung problem), or because the pressure in the heart chamber to where the blood is pumped (left atrium) is increased (heart problem), backing the blood flow up into the lung. Long term, the right side of the heart must pump harder to get the blood through these vessels and through the lungs, potentially leading to heart failure. Budoff and Shinbane (2003); Çobanoğlu et al. (2012); Coche et al. (1998).

Pulmonary hypertension is classified by the World Health Organization according to its causes or associated underlying conditions: Group 1: Pulmonary arterial hypertension (PAH) refers to increased pressure in the vessels caused by obstruction in the small arteries in the lung, for a variety of reasons. These include "idiopathic" (no identifiable cause or underlying contributing condition); drug-related, HIV infection; connective tissue/autoimmune disorders (such as scleroderma) and others. A (2003); Demello and \&amp; Reid (1991); Elliot et al. (1946). Group 2: Pul- 
monary hypertension due to left-sided heart disease (left heart failure, valve disease), Group 3: Pulmonary hypertension due to lung diseases or hypoxemia (low blood oxygen conditions): emphysema/chronic obstructive pulmonary disease (COPD); pulmonary fibrosis/interstitial lung disease; obstructive sleep apnea; chronic high altitude exposure; and other reasons. Group 4: CTEPH (chronic thromboembolic pulmonary hypertension) - blood clots in the lungs blocking blood flow, Group 5: Pulmonary hypertension from numerous other potential metabolic, systemic, or hematologic disorders. Regardless of the cause of pulmonary hypertension, blood flow through the lungs to the left side of the heart is reduced and the pressure inside the vessels increases. This may cause the blood vessel walls to thicken within the lungs and further worsen and puts a strain on the heart to work harder to get the blood through. Hoffbrand et al. (1996); Kearon (2008); Marten (2008); Moraes and Localzo (1997); NIJKEUTER et al. (2008)

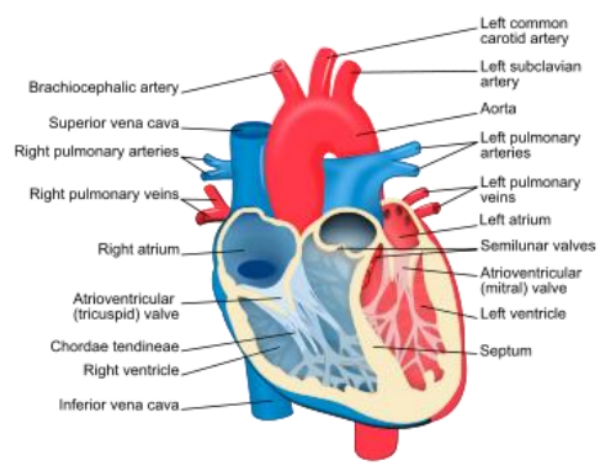

Figure 1 Internal Anatomy of the Heart. (wikipedia.org, 2008) [Stein et al. (1992) ]

\section{MATERIALS AND METHODS}

\subsection{MATERIAL}

\subsubsection{DESIGN OF THE STUDY}

This is a prospective , analytical (which include patients with parenchyma lung disease and normal as control study group).

\subsubsection{AREA AND DURATION OF STUDY}

The data of this study was conducted in the period from November 2019 - January 2020, in Khartoum hospital

\subsubsection{SAMPLE SIZE AND TYPE}

The sample was selected using convenient method, which included 100 patients. 
Sample size will calculated according to the formula:

$\mathrm{N}=\mathrm{s} * \mathrm{z} / \mathrm{d}$

$\mathrm{N}=$ sample size

$\mathrm{Z}=$ confidence level

$\mathrm{S}=$ standard deviation

$\mathrm{D}=$ desired marginal error

\subsubsection{TECHNIQUE}

2.1.4.1 PATIENT PREPARATION A successful CTPA examination depends on careful preparation of the patient before the examination. Such preparation requires that both the technologist and radiologist work together to obtain the appropriate and correct information from the patient and to ensure that the patient understands the procedure. Preceding the CTPA, a patient history was obtained to identify patients with histories of iodine allergy, renal dysfunction, cardiac disease and asthma. Steroid Pre-medication was administrated to those patients with a history of iodine allergy or previous reaction to iodinated contrast agents. Patients with a history of renal dysfunction were further evaluated with creatinine level and blood urea nitrogen level assessed before the procedure. In the other hand we should consider the size of the needle and the site of injection. various size intravenous angiocatheters such as 18 or 20 gauge, and the injection better to be at the elbow Stein et al. (1992).

2.1.4.2 PROTOCOL CT angiography (CTA) is defined as "any CT image of a blood vessel that has been opacified by a contrast medium". During spiral data acquisition, the entire area of interest can be scanned during the injection of contrast. Images can be captured when vessels are fully opacified to demonstrate arterial phase enhancement through the acquisition of data sets (arterial) Stein and Henry (1997).

1. Volume of contrast medium $70-90 \mathrm{ml}$.

2. Rate of injection 4-5 mls.

3. delay : in this study it was better to use (smart-prep) because there was variety in the patients heart rate, a smart-prep is positioned over the pulmonary artery at the level of the carina. After starting the injection the scan is triggered when you can see the contrast at the superior vena cava. or we can use bolus tracking using software supplied with most multi detector scanner Stein and Henry (1997).

4. Detector width- reconstruction (mm)-(0.625-1.25).

5. Scan direction and extension-caudocranial direction helps reduce artifact from contrast in the superior vena cava, less important with faster multislice scanner, scan from hemi diaphragm to the lung apex. Imaging review and postprocessing, imaging should be reviewed at three setting:

- Mediastinal window (window width-window level) (400-40 HU) 
- Pulmonary embolism -specific window (700-100 HU)

- Lung window (1500-600 HU)

Multiplanar reformatted images through the longitudinal axis of a vessel can be helpful to overcome difficulties encountered on axial section of obliquely oriented arteries, adding confidence in diagnosis or" exclusion of thrombus Stein and Henry (1997).

\subsubsection{POST PROCESSING TECHNIQUE}

\subsubsection{VISUALIZATION TOOLS Multiplanar Reconstruction (MPR )}

MPR was the first visualization tool used in CTPA. The reformat was done at the workstation as sagittal, coronal, left and right oblique including curved planes for better diagnose and interpretation of the embolism.

\section{Interpretation}

All the CT images were diagnosed by two professional radiologists and the measurements of the variables were done by one technologist. The measurements were done as the following image:

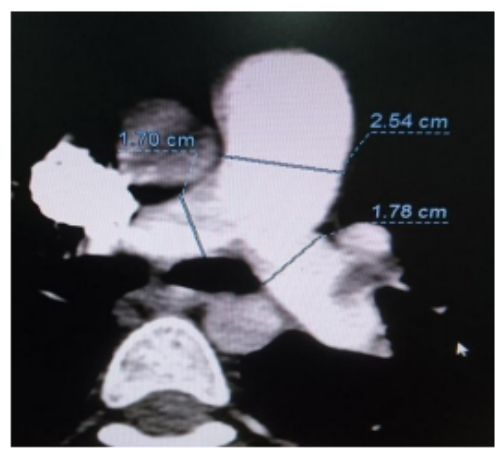

Figure 2 The method of measurement of main pulmonary diameters.

\section{RESULTS}

Table 1 show statistical parameters for all patients

\begin{tabular}{ccccc}
\hline & Age & MPA & RPA & LPA \\
\hline Mean & 47.92 & 27.934 & 19.084 & 19.178 \\
\hline Median & 49.00 & 23.350 & 19.450 & 19.650 \\
\hline Std. Deviation & 19.035 & 28.5980 & 4.0376 & 3.7194 \\
\hline Minimum & 3 & 15.7 & 8.9 & 7.9 \\
\hline Maximum & 80 & 223.8 & 27.0 & 28.3 \\
\hline
\end{tabular}


Table 2 show gender frequency distribution for all patients

\begin{tabular}{ccc}
\hline Gender & Frequency & Percent \\
\hline Female & 42 & 42.0 \\
Male & 58 & 58.0 \\
Total & 100 & 100.0 \\
\hline
\end{tabular}

Table 3 Show correlate between the parameters of pulmonary artery dimension with patients' gender

\begin{tabular}{|c|c|c|c|c|c|}
\hline \multicolumn{6}{|c|}{ Group Statistics } \\
\hline & Gender & $\mathbf{N}$ & Mean & Std. Deviation & Std. Error Mean \\
\hline \multirow[t]{2}{*}{ Age } & Female & 42 & 38.67 & 17.206 & 3.755 \\
\hline & Male & 58 & 54.62 & 17.660 & 3.279 \\
\hline \multirow[t]{2}{*}{ MPA } & Female & 42 & 23.876 & 4.3895 & .9579 \\
\hline & Male & 58 & 30.872 & 37.3654 & 6.9386 \\
\hline \multirow[t]{2}{*}{ RPA } & Female & 42 & 18.029 & 4.9042 & 1.0702 \\
\hline & Male & 58 & 19.848 & 3.1480 & .5846 \\
\hline \multirow[t]{2}{*}{ LPA } & Female & 42 & 17.905 & 4.0506 & .8839 \\
\hline & Male & 58 & 20.100 & 3.2238 & .5986 \\
\hline
\end{tabular}

Table 4 show analysis of variance test for the pulmonary diameter according to the patient gender

\begin{tabular}{|c|c|c|c|c|c|}
\hline \multicolumn{6}{|c|}{ ANOVA } \\
\hline & & Sum of Squares & Mean Square & $\mathbf{F}$ & P. value \\
\hline \multirow[t]{3}{*}{ MPA } & Between Groups & 596.176 & 596.176 & .725 & .399 \\
\hline & Within Groups & 39478.17 & 822.462 & & \\
\hline & Total & 40074.35 & & & \\
\hline \multirow[t]{3}{*}{ RPA } & Between Groups & 40.332 & 40.332 & 2.552 & .117 \\
\hline & Within Groups & 758.495 & 15.802 & & \\
\hline & Total & 798.827 & & & \\
\hline \multirow[t]{3}{*}{ LPA } & Between Groups & 58.696 & 58.696 & 4.550 & .038 \\
\hline & Within Groups & 619.150 & 12.899 & & \\
\hline & Total & 677.846 & & & \\
\hline
\end{tabular}

\section{DISCUSSION}

Pulmonary hypertension is a common disease and needs accurate diagnosis for medical treatment. this study has been done to evaluate the pulmonary arteries in pulmonary hypertensive patients using CT scan.

The study included 100 patients aged between 3 to 80 years old with mean age of $47.92 \pm 19.03$ years old. The study measured the MPA, RPA and LPA, the mean was $27.934 \pm 28.5980,19.084 \pm 4.0376$ and $19.178 \pm 3.7194$ respectively as described in (table 4.1). The study revealed that the male ratio is more than female, it contains 58 males (58\%), and 42 Females (42\%) as described in (table 4.2). The study correlated 
between the parameters of pulmonary artery dimension with patient's gender, it was found that the mean age for females and males is $38.67 \pm 17.2$ years, and $54.6 \pm 17.6$ years respectively.

The study calculated the mean of MPA according to the gender, it was found that the mean for females and males was $23.8 \pm 4.3 \mathrm{~mm}$, and $30.8 \pm 37.3 \mathrm{~mm}$ respectively. The study also calculated the RPA according to the gender, it was found that the mean RPA for females and males was $18.02 \pm 4.9$ and $19.8 \pm 3.1$ respectively. Previous studies were reported that PH should be suspected when pulmonary artery dilated, and pulmonary artery diameter was positively correlated with PAP. Corson et al. (2014); Lin et al. (2009). Devaraj et al found that MPA/AAo could increase the diagnostic value of tricuspid gradient by echocardiography, but it could not identify all patients with PH by one index alone. Considering this, we assumed that multi-index on CT measurement might be better for the diagnosis of $\mathrm{PH}$. According to logistic regression analysis, MPA, RPA, and DAo were involved. If logistic equation was equal to or more than 1, PH should be fully considered. Devaraj et al. (2010)

The study also calculated the LPA according to the gender and was found that the mean LPA for females and males was $17.9 \pm 4.05$ and $20.1 \pm .3 .2$ respectively. As described in (table 4.3). This study correlate between mean pulmonary artery diameter with patients age; it was found that the mean pulmonary artery diameter is increased by $0.075 \mathrm{~mm}$ per each year of age as shown in (figure 4.2).

This study correlate between right pulmonary artery diameter with patients age and it was found that the right pulmonary artery diameter is increased by $0.128 \mathrm{~mm}$ per each year of age as shown in (figure 4.3). The study correlated between left pulmonary artery diameter with patient's age and it was found that the left pulmonary artery diameter is increased by $0.134 \mathrm{~mm}$ per each year of age as shown in (figure 4.4).

\section{CONCLUSION}

The study concluded that the incidence rate of Pulmonary hypertension in males was more than the females with mean age of $47.92 \pm 19.03$ years old. The means measurement of the MPA, RPA and LPA, the mean was $27.934 \pm 28.5980,19.084 \pm 4.0376$ and $19.178 \pm 3.7194$ respectively.

Regarding the study results findings of the (CTPA) performed for clinical suspicion of Pulmonary hypertension lead to Arrhythmias, hemoptysis and pleural effusion were found to be presented in the majority of patients undergoing (CTPA) for the clinical suspicion of Pulmonary hypertension. The presence of pulmonary vessels measurements were found to have correlation with the presence of Pulmonary hypertension, (CT) measurements of right main pulmonary artery and left main pulmonary artery dimensions shown a week correlation with the presence of Pulmonary hypertension with $\mathrm{R} 2=0.36,0.46$ respectively, while there were no correlation with the main pulmonary trunk R2 $=0.10$. and mean of MPA, RPA and LPA according to the 
gender it was found that the mean for the males more than females. Also, study concluded that the mean pulmonary artery diameter is increased by $0.075 \mathrm{~mm}$ per each year of age and correlate between RPA and LPA diameter with patients age it was found that RPA diameter is increased by $0.128 \mathrm{~mm}$ and LPA diameter is increased by $0.134 \mathrm{~mm}$ per each year of age.

\section{REFERENCES}

A, D. (2003). Oxford Textbook of Medicine, 4th Edn. BJA: British Journal of Anaesthesia, 90(6), 813. https://doi.org/10.1093/bja/aeg576

Araoz, P. A., Gotway, M. B., Trowbridge, R. L., Bailey, R. A., Auerbach, A. D., Reddy, G. P., Dawn, S. K., Webb, W. R., \& Higgins, C. B. (2003). Helical CT Pulmonary Angiography Predictors of In-Hospital Morbidity and Mortality in Patients With Acute Pulmonary Embolism. Journal of Thoracic Imaging, 18(4), 207-216. Retrieved from https://dx.doi .org/10.1097/00005382-200310000-00001 10.1097/00005382-200310000-00001

Badesch, R., \& B, D. (2009). Diagnosis and assessment of pulmonary arterial hypertension. Journal of the American College of Cardiology, 54, 55-66.

Bergin, C. J., Hauschildt, H. P., \& Brown, M. A. (1999). identifying the cause of unilateral hypo perfusion in patients suspected to have chronic pulmonary thromboembolism: diagnostic accuracy of helical and conventional angiography. Radiology, 213, 743-749.

Budoff, M. J., \& Shinbane, J. S. (2003). BTS guidelines for the management of suspected acute pulmonary embolism British Thoracic Society. Thorax, 58, 470-83.

Çobanoğlu, G., Ozansoy, M., \& Başak, A. N. (2012). Are alsin and spartin novel interaction partners? (Vol. 427) (No. 1). Rijeka, Croatia: Elsevier BV. Retrieved from https://dx.doi.org/ 10.1016/j.bbrc.2012.08.103 10.1016/j.bbrc.2012.08.103

Coche, E. E., Müller, N. L., Kim, K. I., Wiggs, B. R., \& Mayo, J. R. (1998). Acute pulmonary embolism: ancillary findings at spiral CT. Radiology, 207(3), 753-758. Retrieved from https://dx.doi.org/10.1148/radiology.207.3.9609900 10.1148/radiology.207.3 .9609900

Corson, N., Armato, S. G., Labby, Z. E., Straus, C., Starkey, A., \& Gomberg-Maitland, M. (2014). CT-Based Pulmonary Artery Measurements for the Assessment of Pulmonary Hypertension. Academic Radiology, 21(4), 523-530. Retrieved from https://dx.doi.org/10 .1016/j.acra.2013.12.015 10.1016/j.acra.2013.12.015

Demello, \& \&amp; Reid, L. D. (1991). Arteries and veins. In Crystal, R. West, \& J. B (Eds.), The lung, scientific foundations (pp. 767-777). Raven Press.

Devaraj, A., Wells, A. U., Meister, M. G., Corte, T. J., Wort, S. J., \& Hansell, D. M. (2010). Detection of Pulmonary Hypertension with Multidetector CT and Echocardiography Alone and in Combination. Radiology, 254(2), 609-616. Retrieved from https://dx.doi.org/ 10.1148/radiol.09090548 10.1148/radiol.09090548

Elliot, Reid, L., Euler, \& \&amp; Liljestrand, G. U. (1946). Some new facts about the pulmonary artery and its branching pattern. Acta Physiologica Scandinavica, 16, 301-320.

Estepar, R. S., Kinney, G. L., \& Black-Shinn, J. L. (2013). Computed tomographic measures of pulmonary vascular morphology in smokers and their clinical implications. Am J Respir Crit Care Med, 188(2), 231-239.

Hoffbrand, J. E., Pettit, P. A., Huang, W. M. ., Yen, Rt, Mclaurine, \& Bledsoe, G. (1996). Essential Haematology, Black well science Ltd press. Journal of Applied Physiology, 81, 21232133. 
Kearon, C. (2008). Antithrombotic therapy for venous thromboembolic disease: American college of chest physicians Evidence-Based Clinical Practice Guidelines. Chest, 133, 454-545.

KURIYAMA, K., GAMSU, G., STERN, R. G., CANN, C. E., HERFKENS, R. J., \& BRUNDAGE, B. H. (1984). CT-Determined Pulmonary Artery Diameters in Predicting Pulmonary Hypertension. Investigative Radiology, 19(1), 16-22. Retrieved from https://dx.doi.org/10 .1097/00004424-198401000-00005 10.1097/00004424-198401000-00005

Lin, F. Y., Devereux, R. B., \& Roman, M. J. (2009). The right sided great vessels by cardiac multidetector computed tomography: normative reference values among healthy adults free of cardiopulmonary disease, hypertension, and obesity. Acad Radiol, 16(8), 981-987.

Marten, S. (2008). On diagnostic procedures in pulmonary embolism (US-AB, Ed.). Karoliska University Press.

Moraes, D., \& Localzo, J. (1997). Pulmonary hypertension: newer concepts In diagnosis and management. ClinCardiol, 20, 676-82.

NIJKEUTER, M., ERP, J. M. K.-V., KRUIP, M. J. H. A., SOHNE, M., BÜLLER, H. R., LEEBEEK, F. W. G., $\&$ and, M. V. H. (2008). Incidence of diagnosis of subsegmental pulmonary emboli using multidetector row and single-detector row computed tomography. Journal of Thrombosis and Haemostasis, 6(2), 384-386. Retrieved from https://dx.doi.org/10.1111/ j.1538-7836.2008.02832.x 10.1111/j.1538-7836.2008.02832.x

Singanayagam, A., Chalmers, J. D., Scally, C., Akram, A. R., Al-Khairalla, M. Z., Leitch, L., Hill, L. E., \& Hill, A. T. (2010). Right ventricular dilation on CT pulmonary angiogram independently predicts mortality in pulmonary embolism. Respiratory Medicine, 104(7), 1057-1062. Retrieved from https://dx.doi.org/10.1016/j.rmed.2010.02.004 10.1016/j.rmed.2010.02.004

Stein, P. D., \& Henry, J. W. (1997). Clinical Characteristics of Patients With Acute Pulmonary Embolism Stratified According to Their Presenting Syndromes. Chest, 112(4), 974979. Retrieved from https://dx.doi.org/10.1378/chest.112.4.974 10.1378/chest.112 .4 .974

Stein, P. D., Stein, P. D., Goldhaber, S. Z., Henry, J. W., \& Miller, A. C. (1992). Arterial bloob gas analysis in the assessment of suspected acute pulmonary embolism. Circulation, 85, 78-81.

WASHKO, G. R., PARRAGA, G., \& COXSON, H. O. (2012). Quantitative pulmonary imaging using computed tomography and magnetic resonance imaging. Respirology, 17(3), 432444. Retrieved from https://dx.doi.org/10.1111/j.1440-1843.2011.02117.x 10.1111/ j.1440-1843.2011.02117.x 